http:// bjas.bu.edu.eg

\title{
Experimental Investigation for Horizontal Wind Turbine of Direct-Drive O.A.Abdul_Azim, S.M.Eldmerdash, K.M.Elshazly,O.E.Abdellatif
}

E-mail: Osama.abdellatif@ feng.bu.edu.eg

\begin{abstract}
Wind turbines work by converting the kinetic energy in the wind first into rotational kinetic energy in the turbine and then electrical energy that can be supplied. The objectives of this paper are to design a small wind turbine that is optimized for the constraints that come with residential use of a $0.75 \mathrm{~kW}$ generator for a direct-drive wind turbine and to compare the generator systems for pitch control and for active speed stall control.

The comparison of different generator systems in literature is discussed with the criteria based on the energy yield, cost, and weight. A $150 \mathrm{~W}$ at average $4 \mathrm{~m} / \mathrm{s}, 4$-meter diameter wind turbine designed at a TSR of 4.7. The design and implementation process includes the selection of the wind turbine type and the determination of the blade airfoil, pitch angle distribution along the radius, and chord length distribution along the radius. The pitch angle and chord length distributions are optimized based on conservation of angular momentum and theory of aerodynamic forces on an airfoil.
\end{abstract}

Keywords: Wind turbine, Direct drive, HAWT, Optimization.

\section{Introduction}

The utilization of renewable energies as an alternative for fossil fuels is considerably growing due to an increasing environmental concern and exhaustion of fossil fuels [1], [2]. The focal benefits of the generation of electricity from renewable sources are the infinite availability of the energy sources and elimination of the harmful emissions [3]. In recent years, wind power energy systems are highly considered as a prodigious replacement to the conventional methods of generating electricity. In this method, wind turbines are employed to convert the energy of the flowing air to electricity. In the near future, the improvement of energy harvesting techniques, cost reduction, and low environmental impact will lead the wind energy to produce major portion of the world's energy demands [4]. Fast-forwarding to the 21 st century, wind power application has annually grown at a significant rate of 30\% [5], [6]. A variety of techniques are considered to transfer the wind energy to the power generator, including the application of gearboxes [9] as well as gearless power transmission methods such as direct drive generating system [10].

In a conventional wind tower design, a rotor transfers the wind energy to a rotational shaft. This rotor is connected to a drivetrain, gearbox, and electric generator, which are integrated in a nacelle located at the top of every individual wind tower. Furthermore, a significant sum of power electronics is required to provide reactive power for the generator and to accumulate the power and inject it into the power grid. Application of such system is costly and requires sophisticated control systems. Lastly, placement of the gearbox and generator at such height encounters high expenses associated with maintenance.

The idea behind the latter technique is to incorporate all the disseminated power generation equipment on individual wind towers in a larger central power generation unit. With the introduction of this new approach, the wind power only accommodates a direct generating system, which is coupled with a generator. Moreover, the gearbox is eliminated and the generator can be connected directly to rotor shaft. This will result in enhanced reliability, increased life span, and reduced maintenance cost of the wind turbine. Other benefits of this technique include highenergy transfer rate achievement.

Nevertheless, the application of wind energy is rather challenging. Considering wind as an unsteady source of energy, the intermittent nature of wind speed results in the fluctuation on the wind turbine generator angular velocity [7], [8] and the power generation. Additionally, introduction of a medium in form of direct driven results in a significant alteration of the dynamic characteristics of the system.

To mitigate the effect of the output power fluctuations, different control techniques are applied to regulate the output power of the wind turbine [11-13]. However, the latter issue is yet to be addressed in more details.

This paper presents a model-based flow control technique to maintain a constant frequency at the wind turbine generator. The governing equations of wind system are applied to produce a mathematical model of a direct driven wind energy harvesting system. The model is verified with an implemented model.

\section{Direct-drive concepts}

The rotor of direct-drive generator for wind turbine is directly connected to the rotor hub. Thus, as stated above, the direct-drive concept is operated in low speed. When scaling up the wind turbine, the rotational speed is decreased more and more considering the tip speed limitation. In order to scale up the power of the direct-drive generator, the torque, $T$ must be thus increased in inverse proportion to the decrease of the mechanical angular speed, $\omega_{m}$ by:

$$
P=T \times \omega_{m}
$$


The generator power, $P$ can be also defined as a function of the tangential force density, $F_{d}$, the air gap diameter, $D_{g}$, the axial length, $l_{s}$ and the mechanical angular speed as shown in eq. (2).

$$
P=\frac{\pi}{2} F_{d} \times D_{g}^{2} \times l_{s} \times \omega_{m}
$$

Since the torque is proportional to the air gap diameter squared, the direct-drive generator has a larger diameter to produce higher torque. This higher torque thus demands high tangential force and large air gap diameter of the generator. High tangential force and large air gap diameter result in the increase of materials to maintain the air gap in proper deflection against the normal stress between the rotor and stator. Therefore direct-drive generator concept, which is operated in low speed, has the disadvantages such as high torque rating, large diameter, heavy mass, and high cost compared to the geared generator concept. The direct-drive concept thus is usually designed with a large diameter and small pole pitch to increase the efficiency, to reduce the active material and to keep the end winding losses small. [11]

\section{Methdology}

The major aspect of wind turbine performance like power output and loads are determined by the aerodynamic forces generated by the wind. These can only be understood with a deep comprehension of the aerodynamics of steady state operation. The BEM theory combines two methods to analyze the aerodynamic performance of wind turbine. These are momentum theory and blade - element theory which are used to outline the governing equations for the aerodynamic design and power prediction of a wind turbine rotor. Momentum theory examines the momentum balance on rotating annular stream tube passing through a turbine and blade-element theory examines the forces generated by airfoil lift and drag coefficients at various sections along the blade [14].

The wind power available for conversion mainly depends on the wind speed and the swept area of the turbine:

$$
P=\frac{1}{2} \rho A v^{3}
$$

Where $\rho$ the air density $\left(\mathrm{Kg} / \mathrm{m}^{3}\right)$ is, $A$ is the swept area $\left(\mathrm{m}^{2}\right)$ and $v$ the wind speed $(\mathrm{m} / \mathrm{s})$. Albert Betz (German physicist) concluded in 1919 that no wind turbine can convert more than 16/27 (59.3\%) of the kinetic energy of the wind into mechanical energy turning a rotor (Betz Limit or Betz). The theoretical maximum power efficiency of any design of wind turbine is 0.59 . No more than $59 \%$ of the energy carried by the wind can be extracted by a wind turbine. The wind turbines cannot operate at this maximum limit. The power coefficient $C_{p}$ needs to be factored in equation (1) and the extractable power from the wind is given by:

$$
P=\frac{1}{2} \rho A v^{3} C_{p}
$$

The $C_{p}$ value is unique to each turbine type and is a function of wind speed that the turbine is operating in. In real world, the value of $C_{p}$ is well below the Betz limit (0.59) with values of 0.35 0.45 for the best designed wind turbines.
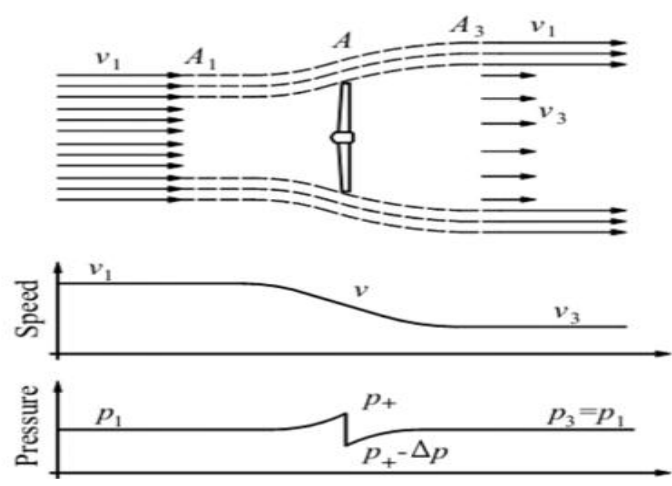

Fig (1) "Diagram of Wind Speed and Pressure Before, During, and After Crossing a Wind Turbine"

By applying the Bernoulli equation to the flow upstream and downstream of the turbine results in Equation (5) and (6), respectively.

$$
\begin{gathered}
p_{1}+\frac{1}{2 \rho v_{1}^{2}}=p_{+}+\frac{1}{2} \rho v^{2} \\
p_{+}-\Delta p+\frac{1}{2} \rho v^{2}=p_{1}+\frac{1}{2} \rho v_{3}^{2}
\end{gathered}
$$

By subtracting Equations (5) and (6), one arrives at the following expression:

$$
\Delta p=\frac{1}{2} \rho\left(v_{1}^{2}-v_{3}^{2}\right)
$$

Based on the change in linear momentum from $v_{1}$ to $v_{3}$, the change in pressure $\Delta p$ can also be expressed as:

$$
\Delta p=\rho v\left(v_{1}-v_{3}\right)
$$

By solving equations (7) and (8) for $v$,

$$
v=\frac{1}{2}\left(v_{1}+v_{3}\right)
$$

The power produced by the wind turbine is equal to the kinetic energy in the air.

$$
P=\frac{1}{2} \rho v\left(v_{1}^{2}-v_{3}^{2}\right)
$$

The axial interference factor $a$ is a factor that represents the loss in wind speed as it approaches the turbine blade. The axial interference factor is defined as:

$$
\begin{gathered}
v=(1-a) v_{1} \\
\text { or, } \quad v_{3}=(1-2 a) v_{1}
\end{gathered}
$$

In terms of the axial interference factor, the power equation from Equation (10) can be rewritten as:

$$
P=2 \rho a(1-a)^{2} v_{1}^{3} A
$$

Using Equation (13) to further define the power extracted by the wind turbine in Equation (2), the coefficient of power can be defined in terms of the axial interference factor only. 


$$
C_{p}=4 a(1-a)^{2}
$$

The maximum theoretical value of the coefficient of performance is determined by setting the derivative of Equation (14) equal to zero and solving for $a$. Doing so results in a root at $a=1 /$ 3 , which corresponds to a maximum coefficient of power of $16 / 27$.

\section{Coefficient of Power- Drag vs. Lift Device}

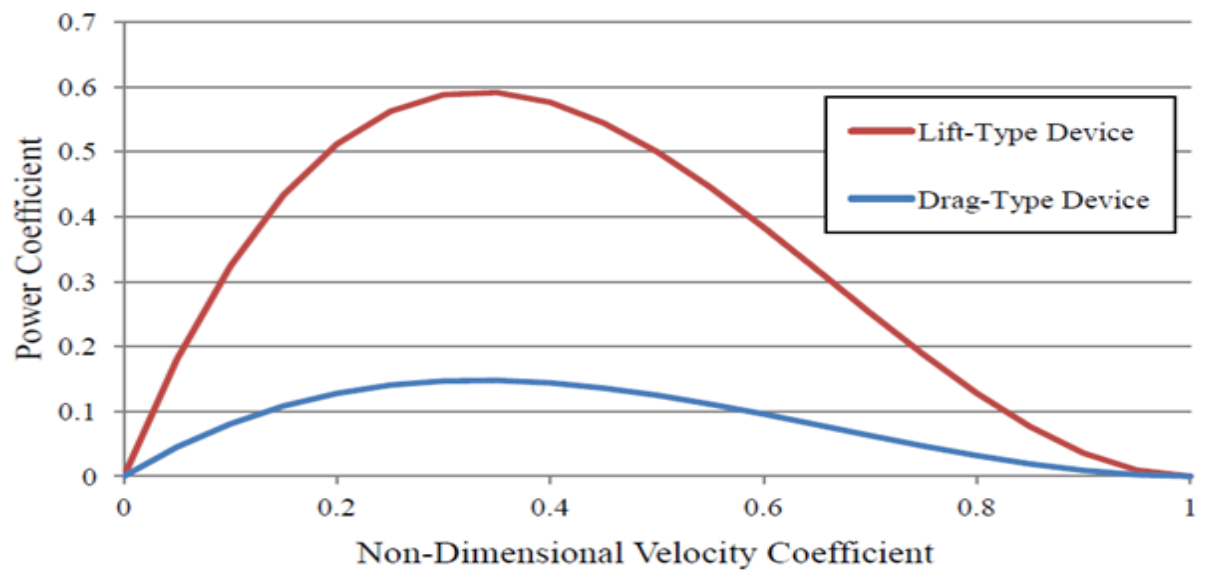

Fig (2) “Coefficient of Power for Lift- and Drag-Type Devices ref. W. L. Kling "Dynamic Modelling of a Wind Turbine"

The power coefficient is not a static value. It varies with tip speed ratio of the wind turbine.

Let $\lambda$ represent the ratio of wind speed $v_{d}$ downstream to wind speed $v_{u}$ upstream of the turbine, i.e.

$$
\begin{gathered}
\operatorname{TSR}(\lambda)=\frac{\text { tangential speed }}{\text { wind speed }}=\frac{v_{d}}{v_{u}} \\
=\frac{\omega r}{v}
\end{gathered}
$$

The power output of a turbine as mentioned is determined by the area of the rotor blades, wind speed and the power coefficient. The output power of the turbine can be varied by changing the area and flow conditions at the rotor system and this forms the basis of the control system. $C_{p}$ is achieved at a particular $\lambda$ which is specific to the design of the turbine.

Hence the model turbine consists of equations (1), power in the wind, equation (2), power

captured by the turbine, and the tip speed ratio of the turbine equation(15).

Control of output of wind energy lies in a number of parameters. The rotor area and flow conditions at the rotor system $\left(v_{w}, \rho, C_{p}\right)$, the rotor torque and pitch angle control. Fixed speed stallregulated turbines have no options for control input. However, variable speed wind turbines use generator torque to control and optimize power output. They also use pitch control to control the output power above their rated wind speed.

Left coefficient

$$
C_{l}=\frac{L}{\frac{1}{2} \times \rho \times v^{2} \times c}
$$

and Drag coefficient

$$
C_{d}=\frac{D}{\frac{1}{2} \times \rho \times v^{2} \times c}
$$

The local angle of attack $\alpha$ is given by the pitch of the airfoil $\theta$; the axial velocity and rotational velocity at the rotor plane denoted respectively by $V_{a}$ and $V_{\text {rot }}$

Angle of attack

$=$ Angle of relative wind to rotor plan-pitch angle

$$
\alpha=\varphi-\theta
$$

Where the flow angle $\varphi$ is found as:

$$
\tan \varphi=\frac{(1-a) v}{\left(1+a^{\prime}\right) \omega r}
$$

The flow angle $\varphi$ varies with axial interference factor $a$, tangential interference factor $a^{\prime}$, wind speed $v$,angular velocity $\omega$, and local radial length $r$.

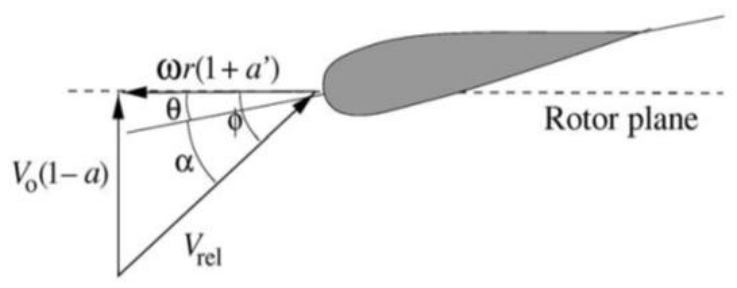

Fig (3) Velocities at the rotor plane

Further, if the lift and drag coefficients $C_{l}$ and $C_{d}$ are known, the lift $L$ and $\operatorname{drag} D$ force per length can be found 
And,

$$
L=\frac{1}{2} \times \rho \times v^{2} \times c \times C_{l}
$$

$$
D=\frac{1}{2} \times \rho \times v^{2} \times c \times C_{d}
$$

Since we are interested only in the force normal to and tangential to the rotor plane, the lift and drag are projected into these directions

And,

$$
P_{N}=L \cos \varphi+D \sin \varphi
$$

So,

$$
P_{T}=L \sin \varphi-D \cos \varphi
$$

And,

$$
C_{n}=C_{l} \cos \varphi+C_{d} \sin \varphi
$$

$$
C_{t}=C_{l} \sin \varphi-C_{d} \cos \varphi
$$

Further, a solidity $\sigma$ is defined as the fraction of the annular area in the control volume which is covered by blades:

$$
\sigma(r)=\frac{c(r) \times B}{2 \times \pi \times r}
$$

$B$ denotes the number of blades, $c(r)$ is the local chord and $r$ is the radial position of the control volume.

From fig (4) it is readily seen from the geometry that

$$
v_{r e l} \sin \varphi=v_{o}(1-a)
$$

And,

$$
\begin{aligned}
& v_{r e l} \cos \varphi= \\
& v_{o}\left(1-a^{\prime}\right)
\end{aligned}
$$

$$
C_{n}=\frac{P_{N}}{\frac{1}{2} \times \rho \times v_{r e l}^{2} \times c}
$$

And,

$$
C_{t}=\frac{P_{T}}{\frac{1}{2} \times \rho \times v_{r e l}^{2} \times c}
$$

Since $P_{N}$ and $P_{T}$ are forces per length, the normal force and the torque on the control volume of thickness $d r$ are:

$$
\begin{gathered}
d T=B \times P_{N} \times d r \\
d M=r \times B \times P_{T} \times d r
\end{gathered}
$$

Using equation (29) for $P_{N}$ and equation (27) for $v_{\text {rel }}$, equation (31) becomes:

$$
\begin{aligned}
d T=\frac{1}{2} \times \rho \times B & \times \frac{v_{o}^{2}(1-a)^{2}}{\sin ^{2} \varphi} \times c \\
& \times C_{n} \times d r
\end{aligned}
$$

Similarly, if equation (30) is used for $P_{T}$ and equations (27) and (28) are used for $v_{r e l}$, equation (32) becomes:

$$
\begin{aligned}
& d M \\
& =\frac{1}{2} \times \rho \times B \\
& \times \frac{v_{o}(1-a) \times \omega r\left(1-a^{\prime}\right)}{\sin \varphi \cos \varphi} \times c \times C_{t} \\
& \times r \times d r \\
& \quad C_{T}=\frac{(1-a)^{2} \times \sigma \times C_{n}}{\sin ^{2} \varphi}
\end{aligned}
$$

If the two equations (31) and (33) for $d T$ are equalized and the definition of the solidity equation (26) is applied, an expression for the axial induction factor $a$ is obtained:

$$
a=\frac{1}{\frac{4 \sin ^{2} \varphi}{\sigma \times C_{n}}+1}
$$

By the same derive $a^{\prime}$,

$$
a^{\prime}=\frac{1}{\frac{4 \sin \varphi \cos \varphi}{\sigma \times C_{n}}-1}
$$

Where chord length can be obtained from the relation,

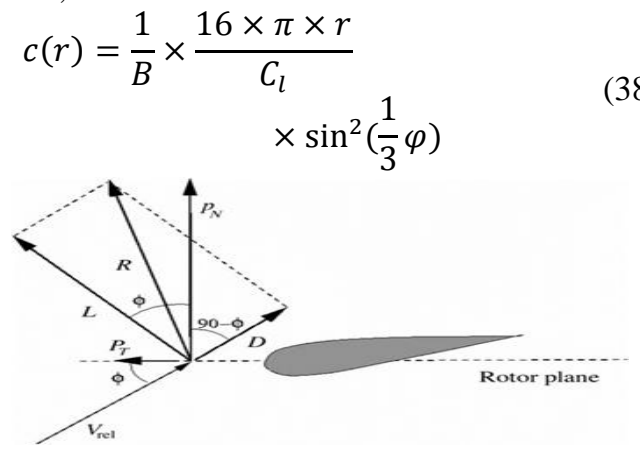

Fig (4) The local loads on a blade

Now all necessary equations for the BEM model have been derived and the algorithm can be summarized. Since the different control volumes are assumed to be independent, each strip can be treated separately and the solution at one radius can be computed before solving for another radius; in other words for each control volume the following algorithm is applied.

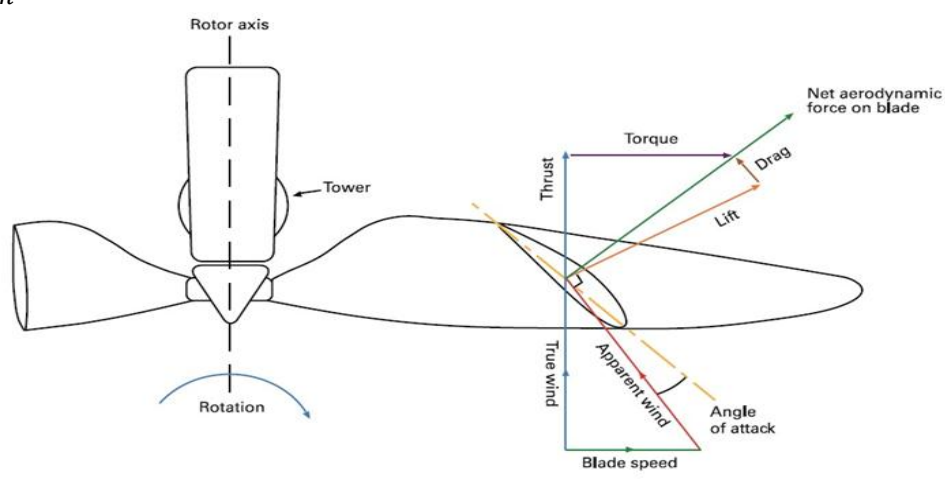

Fig (5) Apparent wind angles 
After applying the BEM algorithm to all control volumes, the tangential and normal load distribution is known and global parameters such as the mechanical power, thrust and root bending moments can be computed. One has to be careful, however, when integrating the tangential loads to give the shaft torque.

The tangential force per length $P_{T}, i$ is known for each segment at radius $r_{i}$ and a linear variation between $r_{i}$ and $r_{i}+1$ is assumed.

The load $P_{T}$ between $r_{i}$ and $r_{i}+1$ is thus:

Where,

$$
P_{T}=A_{i} r+B_{i}
$$

And,

$$
A_{i}=\frac{P_{T, i+1}-P_{T, i}}{r_{i+1}-r_{i}}
$$

$$
B_{i}=\frac{P_{T, i} r_{i+1}-P_{T, i+1} r_{i}}{r_{i+1}-r_{i}}
$$

The torque $d M$ for an infinitesimal part of the blade of length $d r$ is:

$$
d M=r p_{T} d r=\left(A_{i} r^{2}+B_{i} r\right) d r
$$

and the contribution $M_{i}, i+1$ to the total shaft torque from the linear tangential load variation between $r_{i}$ and $r_{i}+1$ is thus:

$$
\begin{aligned}
M_{i, i+1}= & {\left[\frac{1}{3} A_{i} r^{3}+\frac{1}{2} B_{i} r^{2}\right]_{r_{i}}^{r_{i+1}} } \\
\therefore M_{i, i+1}= & \frac{1}{3} A_{i}\left(r^{3}{ }_{i+1}-r_{i}^{2}\right) \\
& +\frac{1}{2} B_{i}\left(r^{2}{ }_{i+1}-r^{2}{ }_{i}\right)
\end{aligned}
$$

The total shaft torque is the sum of all the contributions $M_{i}, i+1$ along one blade multiplied by the number of blades:

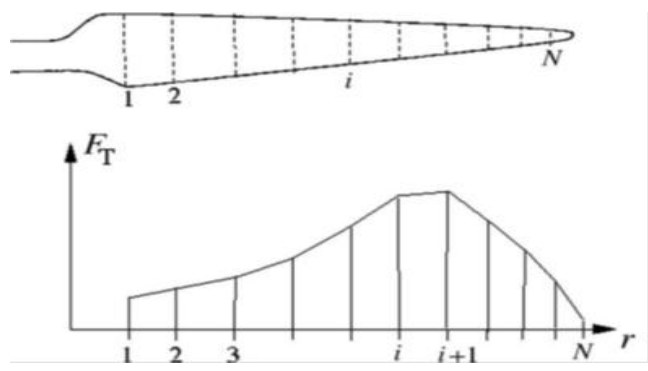

Fig (6) A linear variation of the load is assumed between two different radial positions $r_{i}$ and

$$
r_{i}+1
$$

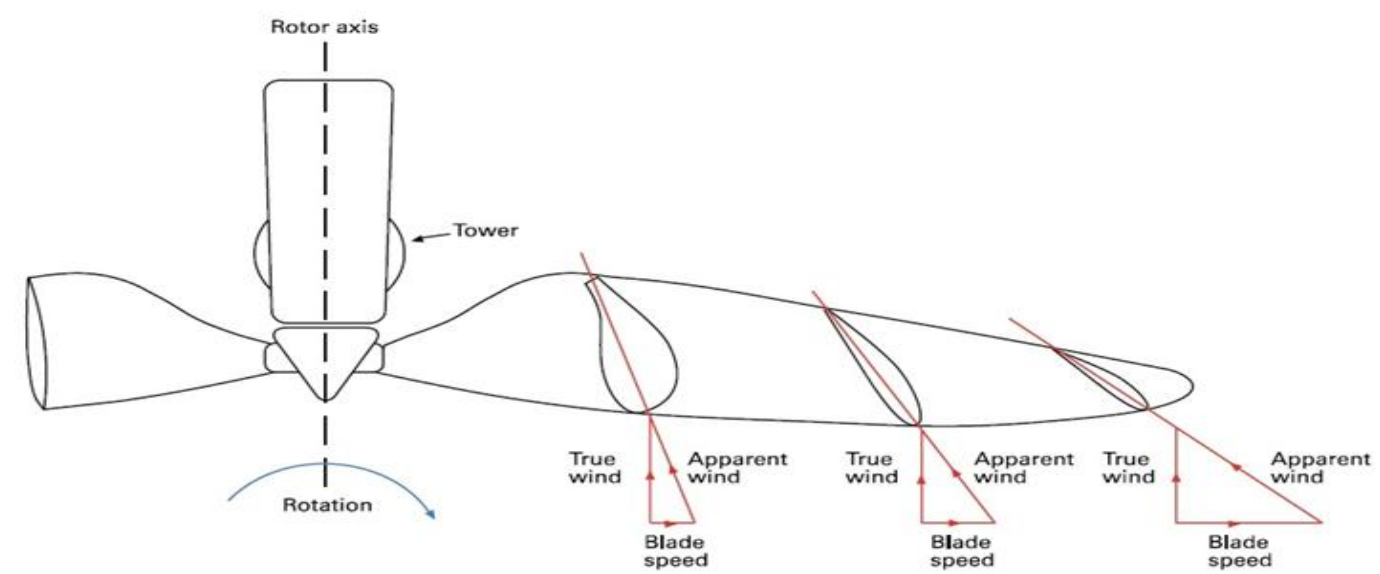

Fig (7) Different apparent wind angles with blade twist

\section{Experimental Test Rig}

A modeling approach is derived by classification into engineering, mathematical, computational and prototype models with a focus on gearbox modeling efforts.

During the design of wind turbines, the strength, the dynamic behavior, and the fatigue properties of the materials and the entire assembly need to be taken into consideration. The wind turbine is built to catch the wind's kinetic energy. As shown in Fig (8), the implemented small wind turbine (SWT) system consists of a horizontal-axis wind turbine (HAWT) and its support structures. A HAWT is a wind turbine whose rotor axis is substantially horizontal, the blades of the wind turbine rotors are fixed. But the blades are shaped in a way that they are adjustable manually in order to adjust the pitch angle to fit with the angle of attack of the airfoil to maximize power output. It has a passive yawing system; it aligns itself to the wind direction using a tail fin. The wind turbine consists of a three-bladed rotor and a nacelle. The rotor has fiber-reinforced blades and a hub as subcomponents. The nacelle has following components: base-structure, yaw-system for rotation,

And bearing for the main power transmission shaft and finally the motor housing. The support structure consists of a tubular steel tower which include the yawing bearing housing and the main pile-foundations which support the wind turbine tower. 


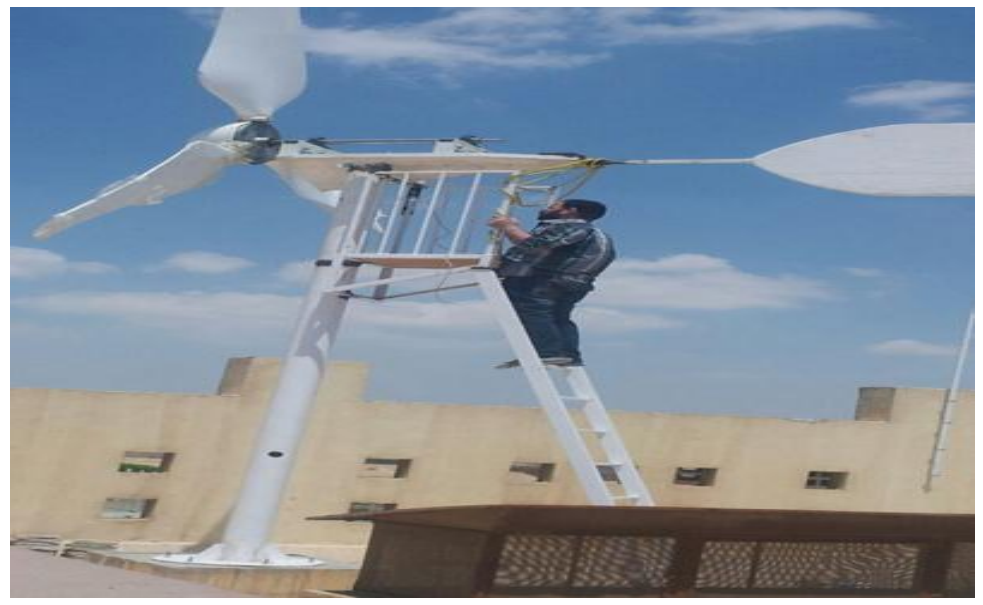

Fig (8) Wind Turbine System

\section{Indirect drive}

The indirect drive is the current dominating design Fig (10), where all components are mounted in line with a gearbox to transfer the low rotational speed from the rotor to a high rotational speed of $1500 \mathrm{rpm}$ needed for $50 \mathrm{~Hz}$ (four-pole generator). With this approach, all components are assembled on a bedplate, which must be stiff enough to prevent misalignment between components. An advantage of this concept is the usage of standard components available on the market. The disadvantage is that the relative high weight comes with the stiff bedplate structure to support all functional components and to prevent misalignments in the drive train system. Compared with the direct drive concept, the generator and the brake are relatively small and therefore have less weight.

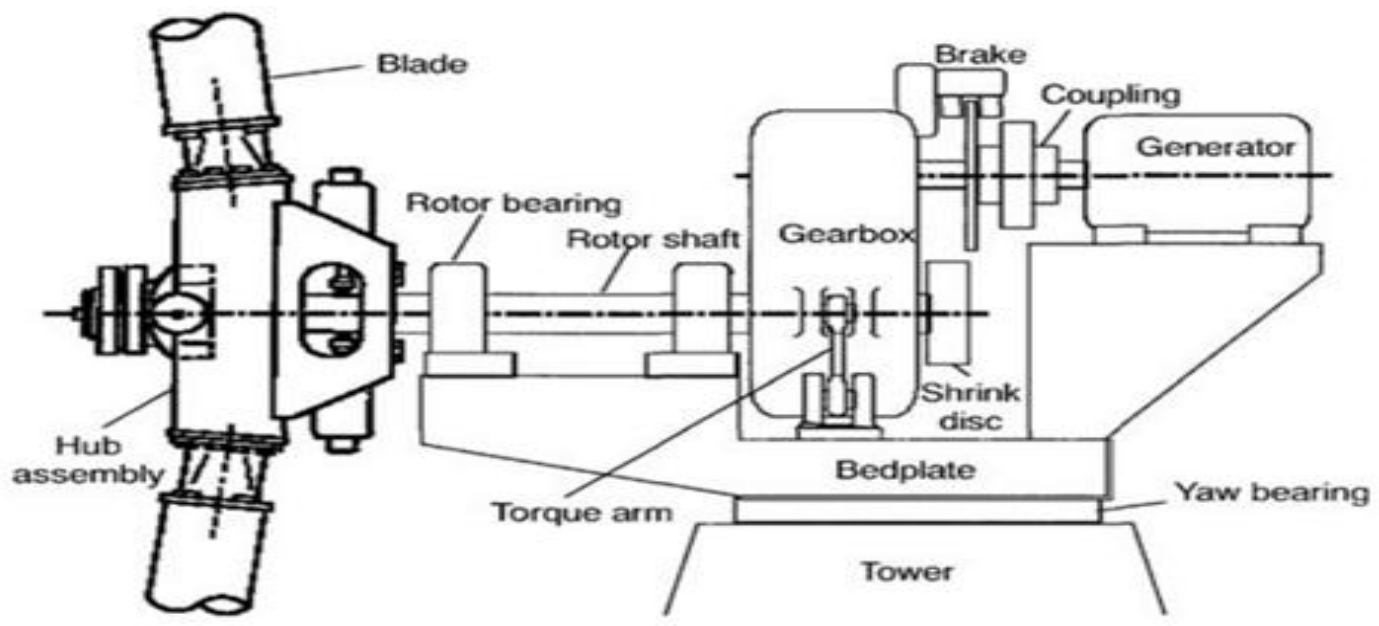

Fig (10) Schematic of an indirect drive train concept, out of American Gear Manufacturers Association Standard. [14]

\section{Direct drive}

This is a gearless concept, where the generator is directly driven by the rotor. To provide the given electrical grid frequency using the low rotational speed from the rotor, a high number of pole is needed to meet this requirement (e.g., 100 pole pairs are needed for $50 \mathrm{~Hz}$ at $30 \mathrm{rpm}$ ). To transfer the power at low rotational speed conditions, a high torque is required.

This high torque accounts mainly for the diameter and the weight of the generator. For rough estimates, the following proportional relationship is used between the torque and the volume of the generator: the torque is linear proportional to the length and squared proportional to the diameter of the generator. Direct drive train system concepts are used in combination with a frequency converter to allow speed variation and to keep the dimensions into acceptable ranges. The advantage of this concept is that it allows a more integrated and compact drive system of a wind turbine. 


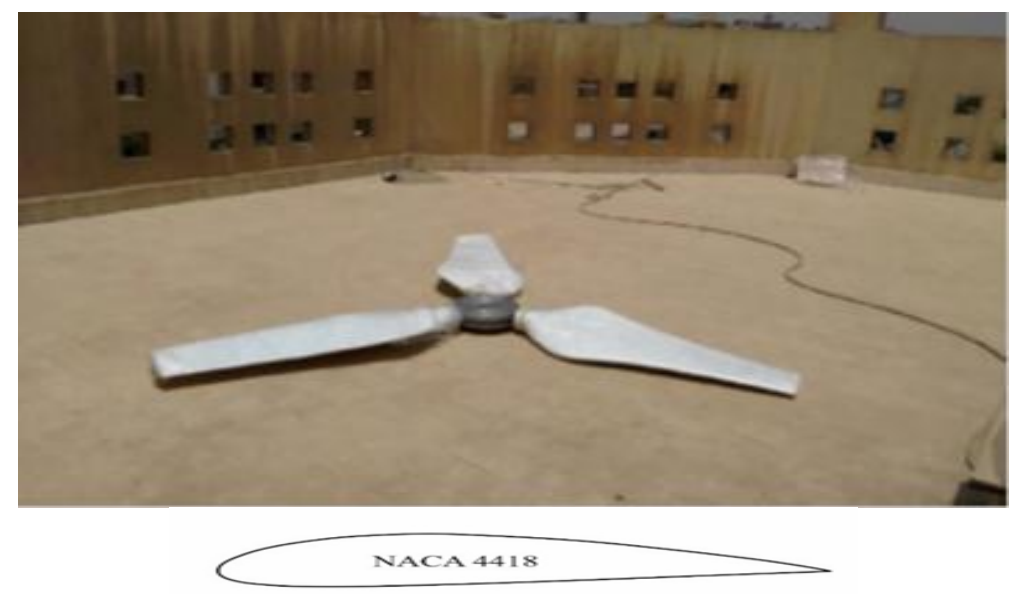

Fig (9) rotor assembly and airfoil profile

The rotor is $4 \mathrm{~m}$ diameter and it consists of an aluminum hub and three blades. The blades are attached to the hub by aluminum male pins Fig (2). The blades are made from fiberglass material, they were formed from a wooden pattern which is manufactured by CNC machine. The male pins of the blades were manufactured separately, then bonded together including an internal steel rod.
The blade is 1.75 length (span). It has a NACA4418 airfoil profile.

Objective of the best airfoil at this application is to maximize the lift coefficient and minimize the drag coefficient at the same conditions (same angle of attack and same Reynolds number).

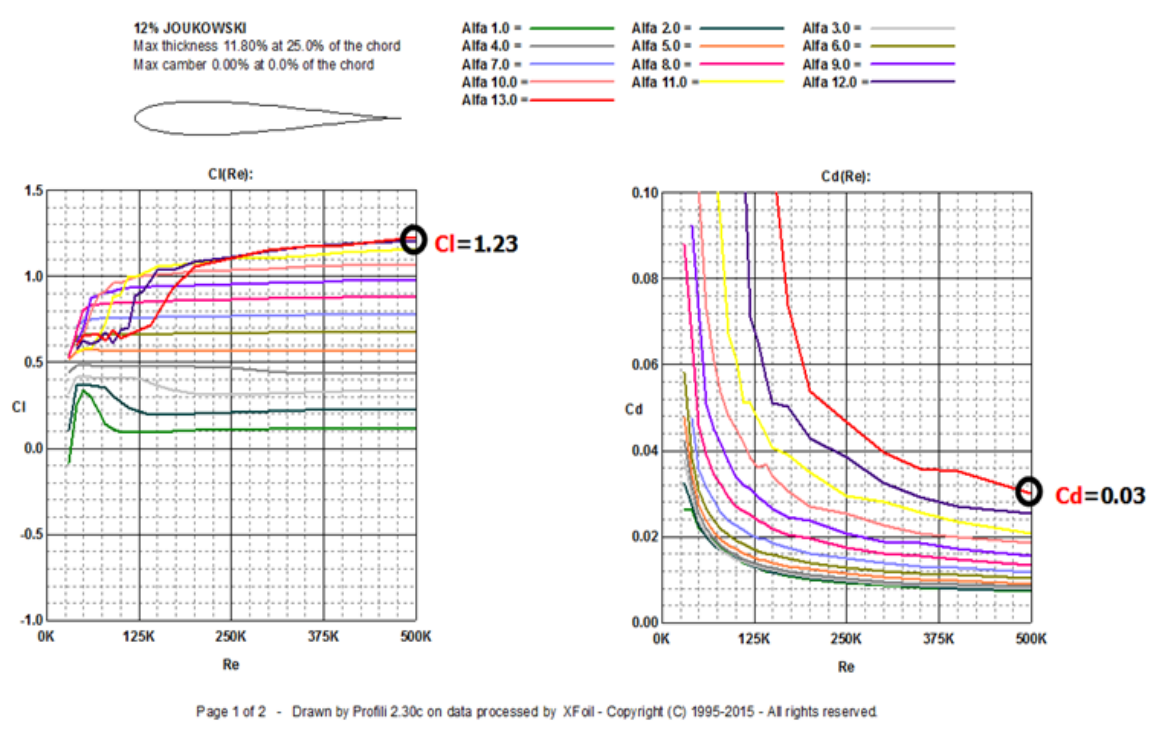

\section{NACA 4418 Airfoil}

With angle of attack $\alpha=13^{\circ}$, Reynolds number $=500,000, C_{l}=1.23, C_{d}=0.03$. Number of blades $(B)=3$

Optimum TSR for 3 blades wind turbine $=4.7$

Fig (9) $C_{l}$ and $C_{d}$ vs Reynolds number with different angle of attack for NACA-4418 using Profili2.3 Average rated wind speed in Egypt $3.43 \mathrm{~m} / \mathrm{s}$ (Hamouda, 2011) ?

Let $v=3 \mathrm{~m} / \mathrm{s}$

Length of the blades $=1.75 \mathrm{~m}$

Radius of the hub $=0.22 \mathrm{~m}$

Swept radius $=$ blade length + hub radius $=2 \mathrm{~m}$ 


\section{Results And discussion \\ Wind power stochastic characteristics play a} significant role in planning, design, and operation of the wind turbines. Theoretically, these characteristics are functions of recorded wind speed behaviors. It is, therefore, necessary to develop analytical relationships between wind speed statistics and wind power characteristics. This study presents;

The output power or torque of a wind turbine is determined by several factors. Among them are (i) turbine speed, (ii) rotor blade tilt, (iii) rotor blade pitch angle (iv) size and shape of turbine, (v) area of turbine, (vi) rotor geometry for a HAWT, (vii) and wind speed. A relationship between the output power and the various variables constitute the mathematical model of the wind turbine. This paper attempts to address part or whole of these general objectives of wind turbine modelling.

A direct drive generator for a wind turbine is characterized by having a very low rotational speed, and hence very high torque for a given power.

Fig (3) shows the power versus speed curves of the wind turbine for various wind speeds at the specific site. It can be seen that the rated turbine speed for the site is $150 \mathrm{rpm}$, which is the rated input speed at the low-speed (LS) side of the MGPM machine.

$$
\omega=\frac{T S R \times v}{R}=\frac{4.7 \times 3}{2}=7.05 \mathrm{rad} / \mathrm{s}
$$

To calculate number of rotation per minute,

$$
\begin{aligned}
N=\frac{30 \times \omega}{\pi}=\frac{30 \times 7.05}{\pi} & \\
& =67.322 \mathrm{rpm}
\end{aligned}
$$

\begin{tabular}{|c|c|c|c|c|c|c|c|c|c|c|c|}
\hline $13:$ & section number & 1 & 2 & 3 & 4 & 5 & 6 & 7 & 8 & 9 & 10 \\
\hline 14 & $r(m)$ & 0.2 & 0.4 & 0.6 & 0.8 & 1 & 1.2 & 1.4 & 1.6 & 1.8 & 2 \\
\hline 15 & pitch angle $(\theta)$ & 30.15365 & 21.94166 & 13.78155 & 8.850249 & 5.824253 & 3.953863 & 2.819483 & 1.823212 & 0 & 0 \\
\hline 16 & Angle of relative wind to rotor plane $(\phi)$ & 43.15365 & 34.94166 & 26.78155 & 21.85025 & 18.82425 & 16.95386 & 15.81948 & 14.82321 & 13 & 13 \\
\hline 17 & Angle of attack $(\alpha)$ & 13 & 13 & 13 & 13 & 13 & 13 & 13 & 13 & 13 & 13 \\
\hline 18 & Lift coefficient (Cl) & 1.23 & 1.23 & 1.23 & 1.23 & 1.23 & 1.23 & 1.23 & 1.23 & 1.23 & 1.23 \\
\hline 19 & Drag coefficient (Cd) & 0.03 & 0.03 & 0.03 & 0.03 & 0.03 & 0.03 & 0.03 & 0.03 & 0.03 & 0.03 \\
\hline 20 & $C x$ & 0.819382 & 0.679881 & 0.527444 & 0.429939 & 0.368484 & 0.329974 & 0.306443 & 0.285678 & 0.247459 & 0.247459 \\
\hline 21 & Cy & 0.917831 & 1.025457 & 1.111577 & 1.152802 & 1.173891 & 1.185292 & 1.191592 & 1.196741 & 1.205224 & 1.205224 \\
\hline 22 & Solidity Ratio $(\sigma)$ & 0.787817 & 0.668451 & 0.485423 & 0.322289 & 0.224408 & 0.167113 & 0.129598 & 0.104445 & 0.084883 & 0.07162 \\
\hline 23 & Chord length $(\mathrm{C})(\mathrm{m})$ & 0.33 & 0.56 & 0.61 & 0.54 & 0.47 & 0.42 & 0.38 & 0.35 & 0,32 & 0,3 \\
\hline 24 & Calculated (a) & 0.278723 & 0.343145 & 0.399187 & 0.401394 & 0.387464 & 0.368035 & 0.341891 & 0.323145 & 0.335733 & 0.298957 \\
\hline 25 & Calculated (a') & 0.47805 & 0.319255 & 0.189235 & 0.111457 & 0.072603 & 0.051993 & 0.039344 & 0.031099 & 0.024546 & 0.020632 \\
\hline 26 & relative velocity & 3.163695 & 3.440579 & 4.000178 & 4.82511 & 5.695073 & 6.501668 & 7.242385 & 7.936938 & 8.858827 & 9.349273 \\
\hline 27 & Lift & 2.437583 & 4.892235 & 7.203521 & 9.278218 & 11.25001 & 13.10253 & 14.70968 & 16.2716 & 18.53356 & 19.35233 \\
\hline 28 & Drag & 0.059453 & 0.119323 & 0.175696 & 0.226298 & 0.27439 & 0.319574 & 0.358773 & 0.396868 & 0.452038 & 0.472008 \\
\hline 29 & P Tangential & 1.62383 & 2.704176 & 3.088986 & 3.243145 & 3.370285 & 3.515033 & 3.664783 & 3.779225 & 3.728691 & 3.893417 \\
\hline 30 & P Normal & 1.818935 & 4.078681 & 6.509973 & 8.695893 & 10.73681 & 12.62628 & 14.25036 & 15.83162 & 18.16023 & 18.96251 \\
\hline 31 & A factor & 5.40173 & 1.924049 & 0.770796 & 0.635699 & 0.723745 & 0.748747 & 0.57221 & -0.25267 & 0.82363 & 1.946708 \\
\hline 32 & B factor & 0.543484 & 1.934556 & 2.626508 & 2.734586 & 2.64654 & 2.616537 & 2.863689 & 4.183499 & 2.246156 & \\
\hline 33 & Moment & 0.133441 & 0.290941 & 0.443763 & 0.595632 & 0.757867 & 0.933875 & 1.116983 & 1.276177 & 1.448749 & \\
\hline 34 & Moment per blade & 6.99743 & & & & & & & & & \\
\hline $35^{\circ}$ & Total moment & 20.99229 & & & & & & & & & \\
\hline
\end{tabular}

Fig (10) NACA-4418 BEM calculation

After dividing the blade into 10 cross sections to calculate design parameters by equations which have been applied for each section in an Excel sheet and after number of iterations for $a$ and ', get final table of results.

Recording wind speed over one year at site which prototype is conducted [High Institute of Engineering, October city, Egypt] to optimize yawing angle and blade pitch angle for two compared systems. As illustrated in Fig (11).

The design is verified by simulation through Computational Fluid Dynamics (CFD) software offers inexpensive solutions to aerodynamic blade analysis problem. In this study CFD models are presented using ANSYS-FLUENT software.

These CFD model values validated using published calibrated lift and drag coefficients evident in the literature. Optimum values of these coefficients as well as a critical angle of attack were found from polar curves of lift, drag and moment modelling data. These data were exploited in order to select the airfoil with best aerodynamic performance for basis of a three-decisional model analogue. 


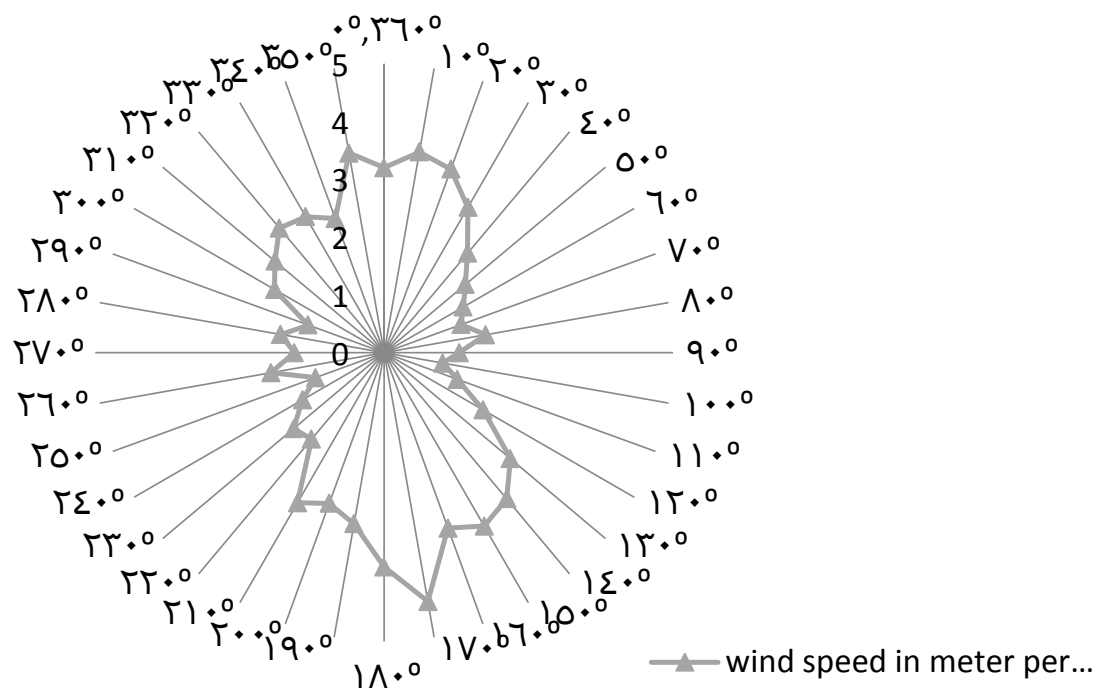

Fig (11) wind rose high institute of engineering, October city, Egypt 2016/2017

Thereafter a three-dimensional CFD model of small horizontal axis wind-turbine was produced. The numerical solution was carried out by simultaneously solving the three-dimensional continuity, momentum and the Naveir-Stokes equations in a rotating reference frame using a standard non-linear $\mathrm{k}-\omega$ solver so that the rotational effect can be studied. These three-dimensional

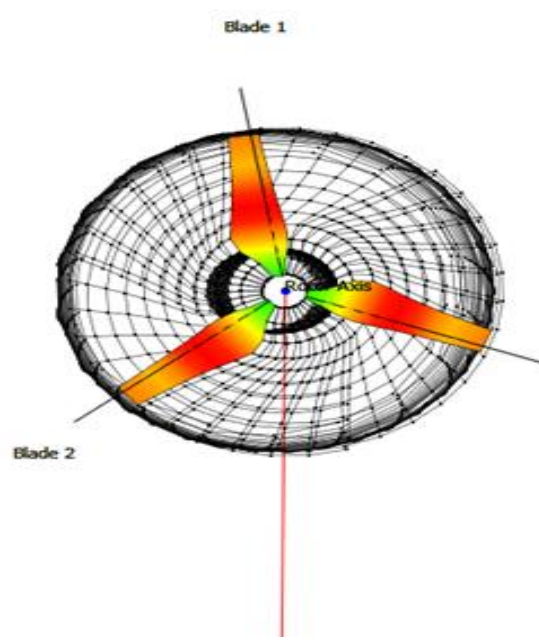

models were used for predicting the performance of a small horizontal axis wind turbine.

By using Qblade software to identify the power of the turbine at wind speed of $3 \mathrm{~m} / \mathrm{s}$ and its power coefficient $\left(C_{p}\right)$.

Pitch range is fixed since designed turbine doesn't have a variable pitch control as in big wind turbines.
Time: $8.88756 \mathrm{~s}$

Power: $0.062974 \mathrm{~kW}$

Cp: 0.303027

$\checkmark$ in $\&$ hub: $3 \mathrm{~m} / \mathrm{s}$

Fig (12) Result of simulation to a wind turbine designed by a Qblade with NACA 4418 airfoil Power coefficient, $C_{p}=0.3$

Power $=62.974 \mathrm{~W}$ at Wind speed $v=3 \mathrm{~m} / \mathrm{s}$

\section{Conclusion}

Use of wind energy for electricity generation purposes is becoming an increasingly attractive energy source partly due to the increase in energy demand worldwide and environmental concerns.

In this paper, a small axis turbine for wind power application was described. The design procedure, mechanical construction, and experimental evaluation of the machine for both induction generator (Geared) and brushless generator (Gearless) configurations were presented. The optimized results show that output voltage and power [34 watt-5.2 $\mathrm{v}$ at average $4 \mathrm{~m} / \mathrm{s}$ ] can be achieved for the gear part, which is comparable with that of typical drive gearless [144 watt-24.88 v at average $4 \mathrm{~m} / \mathrm{s}$ ] for the same angle of attack 
$\alpha=13^{\circ}$. The inherent mechanical friction losses of the geared machine has also been demonstrated, which is a clear advantage for wind power application comparing with mechanical gears.

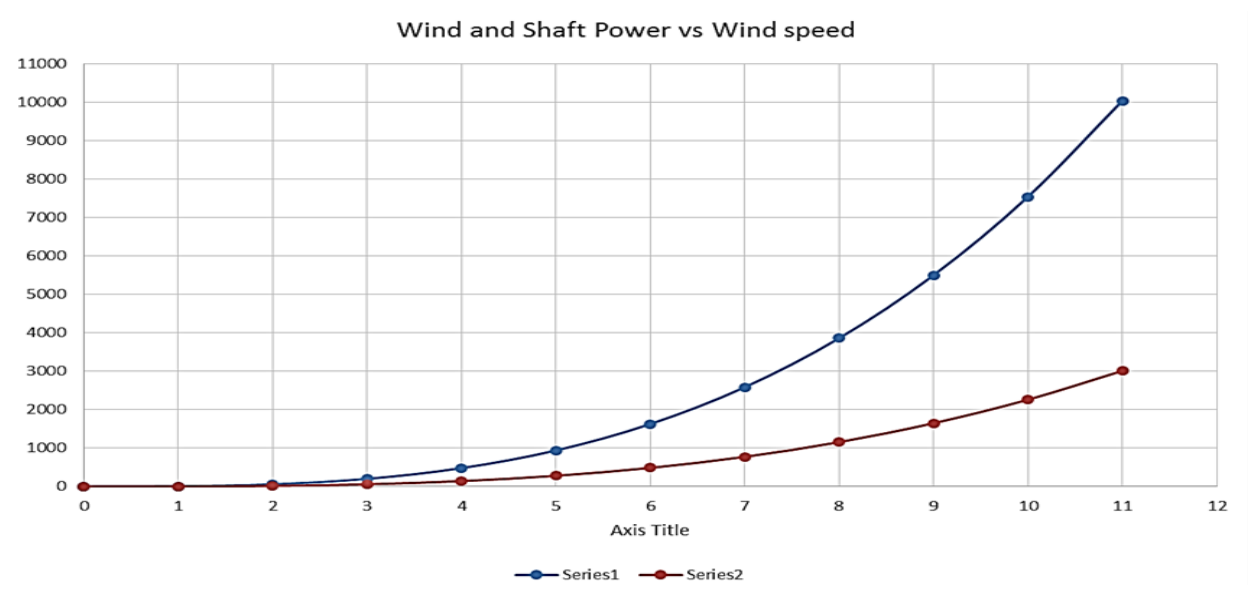

Fig (12) Output voltage of geared (induction machine) and gearless(brushless machine)

[simulated values]

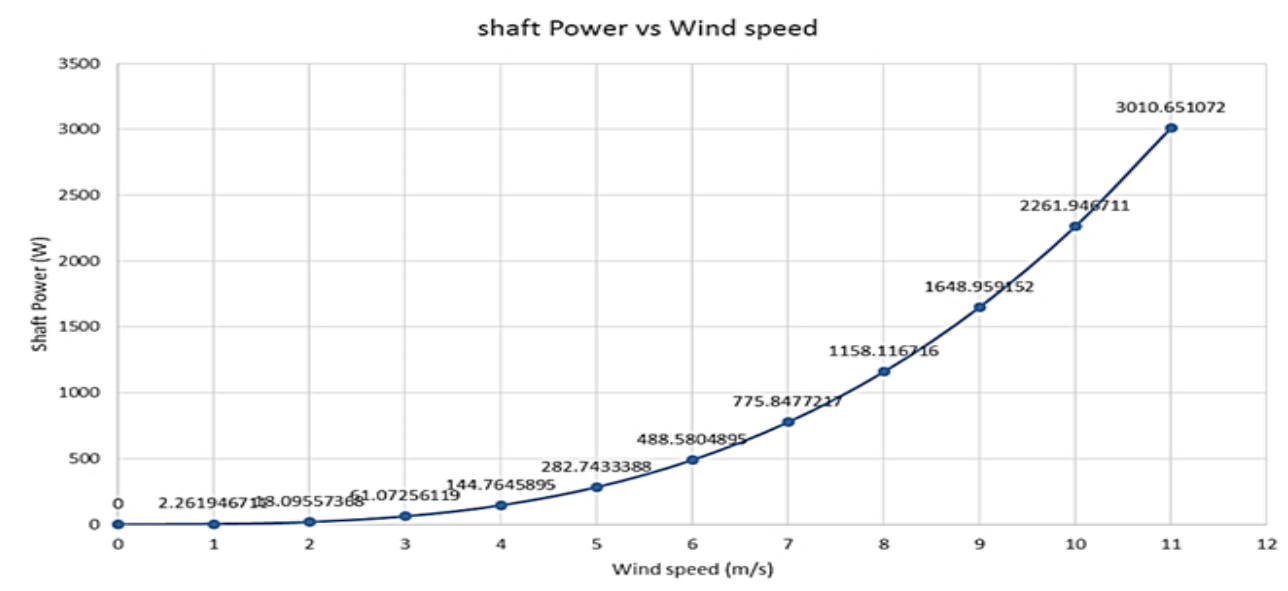

Fig (11) output power using direct drive $0.75 \mathrm{kw}$ generator (measured values)

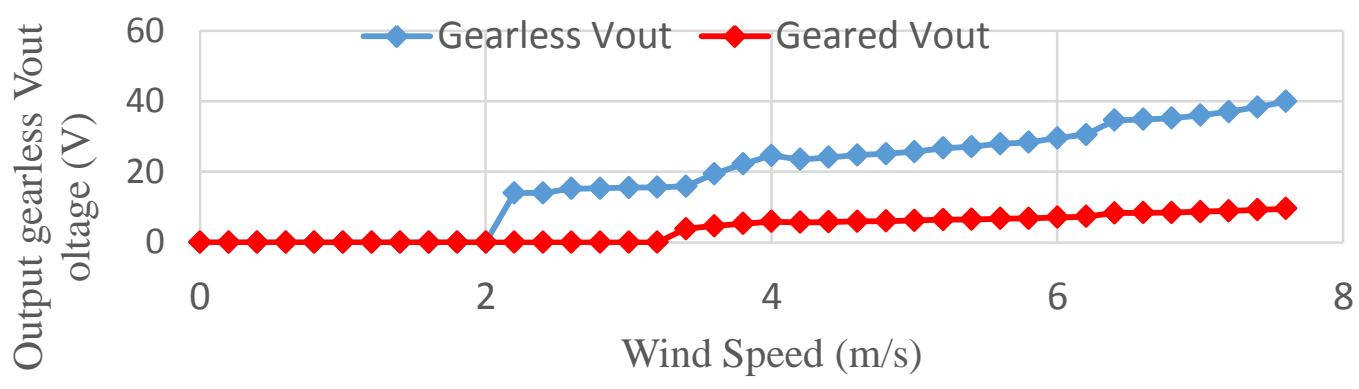

Fig (12) Output voltage of geared (induction machine) and gearless(brushless machine)[measured values] 


\section{References}

[1] A.Ragheb, M.Ragheb, Wind turbine gearbox technologies, Proceedings of the 1st International Nuclear and Renewable Energy Conference (INREC10), 2010.

[2] R-J.Wang, S.Gerber, Magnetically geared wind generator technologies, opportunities and challenges. Applied Energy, vol.136, pp.817$826,2014$.

[3] K.Atallah, D.Howe, A novel high-performance magnetic gear. IEEE Transactions on Magnetics, vol.37(4), pp.2844-2846, 2001.

[4] K.Chau, D.Zhang, J.Jiang, C.Lui, Y.Zhang, Design of a magneticgeared outer-rotor permanent-magnet brushless motor for electric vehicles. IEEE Transactions on Magnetics, vol.43, pp.2504-2506, 2007.

[5] K.Atallah, J.Rens, S.Mezani, D.Howe, A novel pseudo directdrive brushless permanent magnet machine. IEEE Transactions on Magnetics, vol.44(11), pp.4349-4352, 2008.

[6] P.Rasmussen, T.Jahns, H.Toliyat, H.Mortensen, T.Matzen, Motor integrated permanent magnet gear with a wide torquespeed range. IEEE Energy Conversion Congress and Exposition, ECCE, 2009.

[7] Jian L, Chau K, Jiang J. An integrated magnetic-geared permanent magnet in-wheel motor for electric vehicles. IEEE Vehicle Power and Propulsion Conference (VPPC), 2008.

[8] L.Jian, K.Chau, Design and analysis of an integrated halbach-magnetic-geared permanentmagnet motor for electric vehicles. Journal of Asian Electric Vehicles, vol.7(1), pp.12131219, 2009.

[9] T. Senjyu, R. Sakamoto, N. Urasaki, H. Higa, K. Uezato, and T. Funabashi, "Output Power Control of Wind Turbine Generator by Pitch Angle Control Using Minimum Variance Control ," Electrical Engineering in Japan, vol.154(2), 2006.

[10] J. G. Slootweg, H. Polinder, and W. L. Kling "Dynamic Modelling of a Wind Turbine with Doubly Fed Induction Generator," IEEE Power Engineering Society Summer Meeting, 2001.

[11] J. G. Slootweg, S. W. H. de Haan, H. Polinder, and W. L. Klimg, "General Model for Representing Variable Speed Wind Turbine in Power System Dynamics Simulations," IEEE Transaction on Power Systems, vol.183(1),February 2003.
[12] Y.Lei, A. Mullane, G. Lightbody, and R. Yacamini, "Modeling of Wind Turbine with a Doubly Fed Induction Generator for Grid Integration Studies," IEEE Transaction on Energy Conservation. vol. 21(1), March 2006.

[13] “ Wind Energy by 2030 - Increasing Wind Energy's Contribution to U.S. Electricity Supply." U.S. Department of Energy, DOE/GO-102008-2567, May 2008.http://www1.eere.energy.gov/windandhy dro/pdfs/41869.pdf

[14] http://www.awea.org/pubs/factsheets/Market Update.pdf

[15] T. Senjyu, R. Sakamoto, N. Urasaki, H. Higa, K. Uezato, and T.Funabashi , H. Hideki, and H. Sekine, "Output Power Leveling of Wind Turbine Generator for All Operating Regions by Pitch Angle Control," IEEE Transaction on Energy Conversion, vol. 21(2), June 2006.

[16] E. Abdin, and W. Xu, "Control Design and Dynamic Performance Analysis of a Wind Turbine-Induction Generator Unit," IEEE Transaction on Energy Conversion, vol. 15(1), March 2000.

[17] Ragheb, and M. Ragheb, "Wind Turbine Gearbox Technologies," Proceedings of the 1st International Nuclear and Renewable Energy Conference (INREC10), Amman, Jordan, March 2010.

[18] M.A.Yurdusev, R.Ata, N.S.Cetin, Assessment of optimum tip speed ratio in wind turbines using artificial neural networks. Energy, vol31, pp.2153-2161, 2006.

[19] M.M.Duquette, K.D.Visser, Numerical implications of solidity and blade number on rotor performance of horizontal-axis wind turbines. J. Sol. Energy Eng.-Trans. ASME, vol.125, pp.425-432, 2003.

[20] S.Oerlemans, P.Sijtsma, B.M.Lopez, Location and quantification of noise sources on a wind turbine. J. Sound Vib., vol.299, pp.869-883, 2006. J.J.Chattot, Optimization of wind turbines using helicoidal vortex model. J. Sol. Energy Eng. Trans. ASME, vol.125, pp.418-424, 2003.

[21] P.Fuglsang, H.A.Madsen, Optimization method for wind turbine rotors. J. Wind Eng. Ind. Aerodyn., vol.80, pp.191-206, 1999.

[22] M.Jureczko, M.Pawlak, A.Mezyk, Optimisation of wind turbine blades. J. Mater. Proc. Technol., vol.167, pp.463-471, 2005. 
[23] Habali, S.M.; Saleh, I.A. Local design, testing and manufacturing of small mixed airfoil wind turbine blades of glass fiber reinforced plastics Part I: Design of the blade and root. Energy Convers. Manag. 2000, 41, 249-280.

[24] R.W.Thresher, D.M.Dodge, Trends in the evolution of wind turbine generator configurations and systems. Wind Energy, vol.1, pp.70-86, 1998.

[25] P.Gipe, The Wind Industrys Experience with Aesthetic Criticism. Leonardo, Vol.26, pp.243-248, 1993.

[26] D.E.Chamberlain, The effect of avoidance rates on bird mortality predictions made by wind turbine collision risk models. Ibis, vol.148, pp.198-202, 2006.

[27] K.Y.Maalawi, M.A.Badr, A practical approach for selecting optimum wind rotors. Renew. Energy, vol.28, pp.803-822, 2003.

[28] R.T.Griffiths, The effect of aerofoil charachteristics on windmill performance. Aeronaut. J., vol.81, pp.322-326, 1977.

[29] M.Drela, XFoil, Massachusetts Institute of Technology: Cambridge, MA, USA, 2000.
[30] W.A.Timmer, R.P.J.O.M.van Rooij, Summary of the Delft University wind turbine dedicated airfoils. J. Sol. Energy Eng. Trans. ASME, vol.125, pp.488-496, 2003.

[31] I.H.Abbott, A.V. Doenhoff, Theory of Wind Sections; McGraw-Hill: London, UK, 1949.

[32] R.P.J.O.M.Rooij, W.Timmer, Roughness sensitivity considerations for thick rotor blade airfoils.

[33] J. Solar Energy Eng. Trans. ASME, vol.125, pp.468-478, 2003.

[34] P.Fuglsang, C.Bak, Development of the Riso wind turbine airfoils. Wind Energy, vol.7, pp.145-162, 2004.

[35] H.Polinder, Comparison of direct-drive and geared generator concepts for wind turbines. IEEE Trans. Energy Convers, vol.21, pp.725733, 2006.

[36] S.Gupta, J.G.Leishman, Dynamic stall modelling of the S809 aerofoil and comparison with experiments. Wind Energy, vol.9, pp.521-547, 2006.

[37] K.A.Stol, W.X.Zhao, A.D.Wright, Individual blade pitch control for the controls advanced research turbine (CART). J. Sol. Energy Eng. Trans. ASME, vol.128, pp.498-505, 2006. 